\title{
PENGARUH LATIHAN SPLIT SQUAT JUMP TERHADAP KETERAMPILAN KUDA-KUDA ZENKUTSUDACHI ATLET PUTRA FORKI KERINCI
}

\author{
Anggrawawan Janur Putra ${ }^{1}$, Benny Aprial $\mathrm{M}^{2}$ \\ ${ }^{1}$ Universitas Jambi, Jambi, Indonesia, 36361 \\ ${ }^{2}$ STOK Bina Guna, Medan, Indonesia, 20241 \\ anggrawanputra@unja.ac.id․bennyaprial.m@gmail.com²
}

\begin{abstract}
This research aims to find out the or not the effect of Split squat jump training on the skills of Zenkutsudachi horses of male athletes FORKI Kerinci. The research conducted is an experiment with populsi male athletes FORKI detailing which numbers 10 people. In analyzing the data using the t-test that previously conducted the normality test with the liliefors test and the variance homogeneity test with the initial test, namely the test conducted before doing split squad jump exercises and the final test that is a test after doing split squad jump exercises. From the calculation of the right foot test T-count $=10>T$ table 1,833 and left foot Tcount result 9.56 > T-table 1,833. From the analysis conducted it can be concluded that there is a significant influence of split squad jump training on the skills of Zenkutsudachi horses.
\end{abstract}

Keywords : Split squat jump, Zenkutsudachi, Karate

\begin{abstract}
ABSTRAK. Penelitian ini bertujuan untuk mengetahui ada atau tidaknya pengaruh latihan Split squat jump terhadap keterampilan kuda-kuda Zenkutsudachi atlet putra FORKI Kerinci. Penelitian yang dilakukan merupakan penelitian Eksperimen dengan populsi atlet putra FORKI Kerinci yang berjumlah 10 orang. Dalam menganalisis data menggunakan uji-t yang sebelumnya dilakukan uji normalitas dengan uji liliefors dan uji homogenitas varians dengan adanya tes awal yaitu tes yang dilakukan sebelum melakukan latihan split squad jump dan tes akhir yaitu tes setelah melakukan latihan split squad jump. Dari perhitungan Uji-t kaki kanan yaitu T-hitung $=10>$ Ttabel 1,833 dan hasil Uji-t kaki kiri T-hitung 9,56 > T-tabel 1,833. Dari analisis yang dilakukan maka dapat disimpulkan bahwa ada pengaruh yang signifikan latihan split squad jump terhadap keterampilan kuda-kuda Zenkutsudachi.
\end{abstract}

Kata Kunci : Split squat jump, Zenkutsudachi, Karate

\section{PENDAHULUAN}

Awalnya karate diciptakan oleh Darma Guru Budha yang agung, yang berakar di Okinawa melalui kontaknya dengan cina pada pertengahan abad ke-14. Dalam budaya bahasa Jepang karate didasarkan pada istilah "kara" yang berarti kosong dan "te" berarti tangan. "Seni beladiri karate salah satunya adalah seni beladiri yang berasal dari kempo alias seni bela diri tinju Cina (China boxing)" (Nastiti, 2009). "Karate-Do adalah suatu latihan dengan cara melakukan gerakan-gerakan dari seluruh anggota tubuh seperti halnya, menunduk, melompat menjaga keseimbangan maju, mundur bergerak ke kiri/kanan, naik dan turun secara seragam dan bebas. Karate adalah gerak penentu atau kime, yaitu serangan atau tangkisan yang meledak ke sasaran yang dituju dengan 
penggunaan teknik yang tepat dan tenaga yang maksimal dalam waktu yang sesingkatsingkatnya. Kime dapat dilakukan dengan tangan untuk memukul atau menangkis, dan kaki untuk menendang atau menangkis" (Rhadian,2017). Di dalam karate kuda-kuda merupakan salah satu gerakan dasar yang sangat penting karena kuda-kuda merupakan tumpuan dari semua gerakan. salah satu kuda-kuda dalam karate adalah zenkutsudachi, kuda-kuda zenkutsudachi yaitu dimana kaki berada salah satu di depan dan satunya lagi di belakang, dengan lutut kaki depan di tekuk dan kaki belakang lurus, berat badan berada di tengan tengah. Kekuatan bertumpu pada kaki depan. Adapun atlet FORKI Kerinci melakukan gerakan kuda-kuda zenkutsudachi pada saat latihan atau pun bertanding, kemampuan kuda-kuda mereka masih goyang, tidak kuat dan tidak fokus pada gerakan, maka dari itu agar dapat meningkatkan kemampuan para atlet ataupun meningkatkan ketrampilan kuda-kuda Zenkutsudachi. Penulis tertarik memberikan latihan yang akan menunjang keterampilan kuda-kuda Zenkutsudachi yaitu dengan latihan Split squat jump. Saat melakukan kuda-kuda Zenkutsudchi diperlukan tungkai kaki yang kuat dan kemampuan. terutama dalam latihan tahap awal dilatih untuk bisa melakukan gerakan kuda-kuda Zenkutsudachi sebaik-baiknya dengan memfokuskan diri dan mengetahui kihon yang benar (tenik dasar) .

Berdasarkan pengamatan penulis kepada atlet putra FORKI Kerinci, dalam pelaksanaan gerakan kuda-kuda Zenkutsudachi tersebut kurang adanya ketepatan gerakan dalam melakukan kuda-kuda dan kuda-kuda masih sangat lemah sehingga kuda-kuda menjadi goyang. "Keterampilan kuda-kuda Zenkutsudachi ialah teknik kuda-kuda dimana kaki depan ditekuk sehingga posisi lutut berada tegak lurus dengan ibu jari, dan posisi telapak kaki lurus kedepan dengan ibu jari sedikit masuk ke arah dalam. Sedangkan kaki belakang lurus, telapak kaki menapak dengan rata pada lantai, diupayakan diputar kedalam semaksimal mungkin. Pembebanan berat badan (pusat gaya berat) pada kudakuda ini lebih kurang 60\% pada kaki depan, dan 40\% pada kaki belakang" (Simanjuntak,2016). Latihan Split squat jump adalah model latihan untuk meningkatkan kemampuan atlet agar dapat melakukan gerakan menekuk lutut dengan benar dan tepat. Untuk dapat memiliki daya ledak otot tungkai yang baik diperlukan latihan, salah satu bentuk latihan yang dapat dilakukan adalah latihan Split squat jump (Hazildine.2014). 
Berdasarkan uraian diatas penulis tertarik memberikan model latihan untuk mendukung keterampilan kuda-kuda Zenkutsudachi yaitu latihan Split squat jump. Dengan demikian metode latihan Split squat jump merupakan salah satu cara bentuk latihan untuk membentuk kekuatan tungkai kaki dan meningkatkan eksplosif bagian bawah untuk otot tungkai, sejalan dengan tujuan latihan tersebut untuk meningkatkan kemampuan kudakuda Zenkutsudachi yang akan berperan penting dalam meningkatkan kemampuan kekuatan otot tungkai, karena di setiap gerakan karate banyak menggunakan kuda-kuda Zenkutsudachi.

Hipotesis dari penelitian ini yakni adanya pengaruh latihan Split squat jump terhadap keterampilan kuda-kuda Zenkutsudachi atlet putra FORKI Kerinci. Serta tujuan dari penelitian ini yakni seberapa baik pengaruh latihan split squad jump pada kemampuan Zenkutsudachi atlet putra karate FORKI Kerinci.

\section{METODE PENELITIAN}

Penelitian ini menggunakan metode penelitian eksperimen. Adapun desain nya PreExperimental Desain dalam bentuk one group pretest-posttest. Pada desain ini terdapat pretest sebelum diberi perlakuan. Dengan demikian hasil perlakuan dapat diketahui lebih akurat, karena dapat dibandingkan dengan keadaan sebelum perlakuan (Sugiyono, 2018). Dalam penelitian ini peneliti melakukan tes awal (pretest) selanjutnya dilakukan tes akhir (posttest) untuk mengetahui perubahannya. Penelitian dilakukan 16 kali selama 2 bulan yaitu 28 November 2020 sampai 28 Januari 2021 bertempat di dojo FORKI Kerinci. Populasi dan sampel penelitian ini adalah seluruh atlet putra FORKI Kerinci 2018 berjumlah 10 orang. Adapun Variabel penelitian yang diteliti dalam penelitian ini adalah sebagai berikut : a) Variabel Bebas, Variabel bebas adalah variabel penyebab (yang mempengaruhi). Variabel bebas dalam penelitian ini adalah Latihan Split squat jump. b) Variabel Terikat, Variabel terikat adalah variabel yang dipengaruhi. Variabel terikat dalam penelitian ini adalah keterampilan kuda-kuda Zenkutsudachi. 
Table 1. Bentuk Rancangan Penelitian Pre-Test dan Post-Test

\begin{tabular}{ccc}
\hline Pre-test & Perlakuan/treatmen & Post-test \\
\hline $\mathrm{T}_{1}$ & $\mathrm{X}_{1}$ Split Squat jump & $\mathrm{T}_{2}$ \\
\hline
\end{tabular}

Instrumen untuk mengukur keterampilan kuda-kuda Zenkutsudaci yaitu dengan menilai menggunakan lembar Lembar observasi. Adapun peralatan yang dibutuhkan adalah sebagai berikut : (1) Matras, (2) Stopwatch, (3). Peluit, (4) Alat Tulis, (5) Kamera, (6) Formulir Tes, (7) Lembar Observasi.

Teknik pengumpulan data penelitian ini memerlukan beberapa langkah-langkah yang harus dilakukan sebagai berikut.

1. Langkah Persiapan
a. Menyiapkan tenaga pembantu untuk memperlancar jalannya penelitian,
b. Penyusunan jadwal latihan
c. Persiapan alat-alat untuk mempermudah dan memperlancar kegiatan
d. Penyiapan format isian data

2. Langkah Pelaksanaan

a. Tes Awal

1) Peneliti menyiapkan instrumen

2) Atlet yang akan melakukan tes diberi kesempatan untuk melakukan pemanasan selama 10 menit

3) Atlet diposisikan tidak mengganggu atlet yang sedang melaksanakan tes, dan menunggu giliran pengambilan tes keterampilan kuda-kuda Zenkutsdachi.

4) Siswa dipanggil satu persatu kemudian penguji bersiap, atlet melakukan keterampilan kuda-kuda Zenkutsudachi kaki kanan di depan dan Zenkutsudachi kaki kiri di depan.

5) Hasil skor siswa dicatat di dalam formulir tes, kemudian siswa berikut dipanggil hingga siswa yang menjadi sampel habis.

6) Terakhir skor masing-masing siswa dijumlahkan untuk siap diolah. 
Tabel 2. Norma tes Keterampilan kuda-kuda Zenkutsudachi

\begin{tabular}{ccc}
\hline NO & $\begin{array}{c}\text { Nilai keterampilan kuda-kuda } \\
\text { Zenkutsudachi kaki kanan }\end{array}$ & Katagori \\
\hline 1 & $10-12$ & Sangat baik \\
2 & $7-9$ & Baik \\
3 & $4-6$ & cukup \\
4 & $0-3$ & Kurang \\
\hline
\end{tabular}

b. Perlakuan

Latihan dilakukan sebanyak 6 minggu ( 3 kali seminggu) dengan tahap-tahap yang sudah ditentukan.

c. Tes Akhir

Setelah dilakukan perlakuan sebanyak 6 minggu, maka dilaksanakan tes akhir terhadap semua atlet yang menjadi sampel. Dari data tes akhir inilah dapat dilihat hasil latihan Split squat jump terhadap keterampilan kuda-kuda Zenkutsudachi.

Teknik analisis data dilakukan untuk menguji hipotesis yang telah dirumuskan. Uji hipotesis yang digunakan adalah Uji-t. Untuk melakukan Uji-t populasi harus berdistribusi normal dan bervariasi Homogen.

Untuk menguji hipotesis digunakan uji statistik melalui perhitungan rata-rata yang bertujuan untuk menentukan apakah hasil yang diperoleh dari latihan Split squat jump berpengaruh terhadap sampel pada keterampilan kuda-kuda Zenkutsudachi, yang menggunakan pre-test dan post-test one group design, maka penguji hipotesis tersebut menggunakan uji-t. Uji hipotesis menggunakan uji-t sebagai berikut :

$$
=\frac{\bar{X}_{1}-\bar{X}_{2}}{\sqrt{\frac{s_{1}^{2}}{n_{1}}+\frac{s_{2}^{2}}{n_{2}}-2 r\left(\frac{s_{1}}{\sqrt{n_{1}}}\right)\left(\frac{s_{2}}{\sqrt{n_{2}}}\right)}}
$$

\section{HASIL DAN PEMBAHASAN}

\section{Hasil Penelitian}

Hasil pengukuran jumlah keterampilan kuda-kuda Zenkutsudachi atlet putra FORKI Kerinci, adalah sebagai berikut. 
Tabel 3. Hasil tes keterampilan kuda-kuda Zenkutsudachi

\begin{tabular}{lccccc}
\hline \multicolumn{1}{c}{ Keterangan } & Rata-rata & Sd & Varian & Maximum & $\begin{array}{c}\text { Jumlah } \\
\text { nilai } \\
\text { Minimum }\end{array}$ \\
\hline $\begin{array}{l}\text { Pretest kaki kanan } \\
\text { didepan }\end{array}$ & 5,2 & 1,47 & 2,17 & 7 & 3 \\
$\begin{array}{l}\text { Postest kaki kanan } \\
\text { didepan }\end{array}$ & 6,6 & 1,17 & 1,37 & 8 & 5 \\
Pretest kaki kiri didepan & 4,5 & 1,07 & 1,16 & 6 & 3 \\
Postest kaki kiri didepan & 6,4 & 1,42 & 2,04 & 8 & 4 \\
\hline
\end{tabular}

a. Tes Awal

Dalam tes awal kuda-kuda Zenkutsudachi kaki kanan di depan ini didapatkan hasil jumlah keseluruhan tes kemampuan dengan nilai 52, dengan demikian dapat dirataratakan hasil tes keterampilan kuda-kuda Zenkutsudachi pada atlet putra FORKI Kerinci adalah 5,2 maka hasil tes awal keterampilan kuda-kuda Zenkutsudachi dapat dikategorikan masih kurang stabil.

Dalam tes awal kuda-kuda Zenkutsudachi kaki kiri di depan didapatkan hasil jumlah keseluruhan tes keterampilan dengan nilai 4,5, dengan demikian dapat dirataratakan hasil tes keterampilan kuda-kuda Zenkutsudachi kaki kiri di depan pada atlet putra FORKI Kerinci adalah 4,5 maka hasil tes awal keterampilan kuda-kuda Zenkutsudachi kaki kiri di depan dapat di kategorikan masih kurang stabil.

b. Tes Akhir

Pada tes akhir kuda-kuda Zenkutsudachi kaki kanan ini didapatkan jumlah keseluruhan kemampuan tes yaitu 6,6. Dengan demikian rata-rata hasil tes keterampilan kuda-kuda Zenkutsudci kaki kanan yang sebesar 6,6, maka hasil tes akhir kuda-kuda Zenkutsudachi kaki kanan dikatagorikan sangat memuaskan.

Tes akhir kuda-kuda Zenkutsudachi kaki kiri didapatkan jumlah keseluruhan kemampuan tes yaitu 6,4. Dengan demikian rata-rata hasil tes keterampilan kuda-kuda Zenkutsudachi kaki kiri yang sebesar 6,4, maka hasil tes akhir kuda-kuda Zenkutsudachi kaki kiri dikatagorikan sangat memuaskan 


\section{Uji Normalitas}

Uji Normalitas yang digunakan adalah Uji Lillierfors bertujuan untuk mengetahui apakah data penelitian yang diperoleh berdistribusi normal atau tidak. Jika dari hasil Uji Normalitas diperoleh (Ltabel > Lhitung) maka data dikatakan normal, jika (Ltabel < Lhitung) maka data tidak normal.

Tabel 4. Tabel hasil Uji Normalitas

\begin{tabular}{clcccc}
\hline NO & \multicolumn{1}{c}{ Kelas } & $\mathbf{N}$ & Lhitung & Ltabel & keterangan \\
\hline 1 & Data tes awal kaki kanan & 10 & 0,1319 & 0,258 & Normal \\
\hline 2 & Data tes awal kaki kiri & 10 & 0,1772 & 0,258 & Normal \\
\hline 3 & Data tes akhir kaki kanan & 10 & 0,1950 & 0,258 & Normal \\
\hline 4 & Data tes kiri kaki kiri & 10 & 0,1451 & 0,258 & Normal \\
\hline
\end{tabular}

2. Uji Homogenitas

Dari hasil uji homogenitas keterampilan kuda-kuda Zenkutsudachi kaki kanan diperoleh hasil Fhitung $=1,256<$ Ftabel $=3,18$ maka dapat disimpulkan data diatas mempunyai Varians Homogen.

Tabel 5. Hasil Uji Homogenitas Zenkutsudachi Kaki Kanan

\begin{tabular}{ccccccc}
\hline No & Kelas & N & S & F hitung & Ftabel & keterangan \\
\cline { 1 - 4 } 1 & Data tes awal (pre-test) & 10 & 1,47 & \multirow{2}{*}{1,256} & 3,18 & Homogen \\
\cline { 1 - 3 } & Data tes akhir (post-test) & 10 & 1,17 & & & \\
\hline
\end{tabular}

Hasil Uji Homogenitas keterampilan kuda-kuda Zenkutsudachi kaki kiri diperoleh hasil Fhitung $=1,327<$ Ftabel $=3,18$ maka dapat disimpulkan data diatas mempunyai Varians Homogen.

Tabel 6. Hasil Uji Homogenitas Zenkutsudachi kaki kiri didepan

\begin{tabular}{ccccccc}
\hline No & Kelas & N & S & Fhitung & Ftabel & keterangan \\
\cline { 1 - 4 } 1 & Data tes awal (pre-test) & 10 & 1,07 & & & \\
\cline { 1 - 3 } & Data tes akhir (post-test) & 10 & 1,42 & & \multirow{2}{*}{1,327} & Homogen \\
\hline
\end{tabular}




\section{Uji Hipotesis}

Dari tabel diatas dan perhitungan di atas dapat diketahui, nilai Thitung $=10>$ Ttabel $=1,833$. Ini berarti HI diterima dan HO ditolak.

Tabel 7. Hasil Analisis Uji-t kaki kanan didepan

\begin{tabular}{|c|c|c|c|c|c|}
\hline Kelas & $\mathbf{N}$ & $\mathbf{S}$ & $T_{\text {tabel }}$ & $T_{\text {hitung }}$ & keterangan \\
\hline Pre-test & 10 & 1,47 & \multirow{3}{*}{1,833} & \multirow{3}{*}{10} & Diterima pada \\
\hline & & & & & tingkat \\
\hline Post-test & 10 & 1,17 & & & $\begin{array}{c}\text { kepercayaan } \\
95 \%\end{array}$ \\
\hline
\end{tabular}

Dari tabel diatas dan perhitungan di atas dapat diketahui, nilai T-hitung $=9,56>$ T-tabel $=1,833$. Ini berarti $\mathrm{HI}$ diterima dan $\mathrm{HO}$ ditolak.

Tabel 8. Hasil Analisis Uji-t kaki Kiri didepan

\begin{tabular}{cccccc}
\hline Kelas & $\mathbf{N}$ & $\mathbf{S}$ & $\mathbf{T}_{\text {tabel }}$ & $\mathbf{T}_{\text {hitung }}$ & keterangan \\
\hline Pre-test & 10 & 1,07 & & & $\begin{array}{c}\text { Diterima pada } \\
\text { tingkat } \\
\text { kost test }\end{array}$ \\
& 10 & 1,42 & & & $\begin{array}{c}\text { kepercayaan } \\
95 \%\end{array}$ \\
\hline
\end{tabular}

\section{Pembahasan}

Berdasarkan hasil Analisis dari tes awal sampai tes akhir Zenkutsudachi kaki kanan di depan diperoleh nilai pada $t_{\text {hitung }}$ sebesar 10 bila dibandingkan dengan $t_{\text {tabe }} 1$ 1,833.dan Zenkutsudachi kaki kiri di depan diperoleh nilai pada $t_{\text {hitung }}$ sebesar 9,56 bila dibandingkan dengan $t_{\text {tabel }} 1,833$ Ini menunjukkan terdapatnya pengaruh yang berarti. Hal ini disebabkan oleh pelaksanaan latihan Split squat jump yang melatih otot tungkai sehingga berpengaruh pada daya tahan otot tungkai pada atlet putra FORKI Kerinci. Pada saat penelitian dilakukan, latihan dilakukan sebanyak 18 kali pertemuan dengan frekuensi 3 kali seminggu. Hal ini menunjukkan bahwa sudah jelas hasil yang diperoleh pada tes akhir dan tes awal, karena sampel telah diberi perlakuan maka semakin baik hasil yang diperoleh.

Dari Analisis data yang dilakukan, ternyata Hipotesis alternatif (Ha) yang dikemukakan dalam penelitian ini dapat diterima kebenarannya dengan menunjukan tes awal dan tes akhir berbeda, dengan kata lain terjadi peningkatan antara tes awal dan tes akhir, dan dapat disimpulkan bahwa terdapat pengaruh penelitian latihan Split squad jump terhadap keterampilan kuda-kuda Zenkutsudachi pada atlet putra FORKI Kerinci. 
Hasil penelitian diketahui adanya pengaruh latihan Split squad jump terhadap keterampilan kuda-kuda Zenkutsudachi atlet putra FORKI Kerinci. Latihan Split squad jump yang mengarah pada gerakan kaki yang dilakukan dengan terprogram serta seimbang akan dapat memberikan peningkatan pada keterampilan kuda-kuda Zenkutsudachi pada atlet putra FORKI Kerinci.

Dengan demikian latihan Split squad jump dapat meningkatkan keterampilan kudakuda Zenkutsudachi yang baik terbukti dari hasil tes awal sebelum di beri latihan, hasil tes kemampuan keterampilan kuda-kuda Zenkutsudachi atlet yang kurang, kemudian setelah diberikan latihan selama delapan belas kali pertemuan dan dilakukan tes akhir hasil keterampilan kuda-kuda Zenkutsudachi atlet pun meningkat. Dengan demikian latihan Split squat jump dapat memberikan pengaruh yang Signifikan

\section{KESIMPULAN}

Berdasarkan Analisis data hasil penelitian diketahui bahwa terdapat pengaruh latihan Split squat jump terhadap keterampilan kuda-kuda Zenkutsudachi pada atlet putra FORKI Kerinci. Pada tes awal kuda-kuda Zenkutsudachi kaki kanan di depan terdapat nilai rata-rata 5,2 dan setelah diberi perlakuan latihan Split squad jump nilai rata-rata meningkat yaitu 6,6. Begitu juga dengan keterampilan kuda-kuda Zenkutsudachi kaki kiri di depan terdapat nilai rata-rata 4,5 dan setelah diberi perlakuan latihan Split squad jump nilai ratarata meningkat yaitu 6,4. Maka dapat disimpulkan bahwa latihan Split squad jump dapat meningkatkan keterampilan kuda-kuda Zenkutsudachi. Meskipun apabila dilihat dari perbedaan rata-rata kaki kanan di depan lebih baik dari pada kaki kiri didepan hal tersebut di karenakan gerakan dominan dan kebiasaan yang dilakukan atlet tersebut. Sehingga di perlukan penelitian lebih lanjut yang mendukung terhadap penampilan karateka agar lebih baik.

\section{DAFTAR PUSTAKA}

Anwar, Muhammad. 2013. Teknik kihon Karate. Cerdas Jaya. Jakarta

Manullang, J. G. (2018). Pengaruh Latihan Split Squat Jump Dan Latihan Maegeri Dari Posisi Jongkok Terhadap Kecepatan Tendangan Maegeri Chudan Pada Atlet Karateka Putera Sabuk Hijau Perguruan Wadokai Dojo Ketsu 1 Palembang. Halaman Olahraga Nusantara (Jurnal Ilmu Keolahragaan), 1(2), 220-228.

Nastiti. 2008. Menjadi karateka. Be Champion. Jakarta

Nurhasan. 2018. Tes dan Pengukuran dalam pendidikan jasmani. Direktoral jendral olahraga. Jakarta 
Rozi, F. (2021). Analisis teknik dasar kuda-kuda zenkutsu dachi pada beladiri karate. Fair Play: Indonesian Journal of Sport, 1(1), 7-12.

Rukajat, A., Abas, T. T., \& Gusniar, I. N. (2021). Pelatihan Seni Bela Diri Karate Teknik Zenkutsu Dachi pada Siswa SMP Negeri 1 Karawang Barat. Jurnal Pendidikan Tambusai, 5(3), 8065-8069.

Simanjuntak, Victor G. 2016. Teknikdasar karate. Cerdas Jaya. Jakarta

Simbolan Midun Santosa. 2016. Pengaruh latihan split jump dan fleksibilitas terhadap kemampuan tendangan mawashi geri paa atlet karate inkai perternakan jambi (Skripsi). Universitas jambi. Jambi.

Simbolon,B. 2018 Latihan dan melatih karate. Griyapustaka. Yogyakarta.

Sugiyono. 2017. Metode penelitian kuantitatif. Alfabeta. Bandung

Sukadiyanto. 2016. Pengantar teori dan metodologi melatih fisik. LubukAgung. Bandung

Sunarno agung. 2015. Metode penelitian keolahragaan. Yuma pustaka. Surakarta

Suparno. 2014. Tingkat ketrampilan dasar dalam bermain futsal siswa kelas V SD negri gondoloyu Yogyakarta tahun 2014/2015 (Skripsi). Universitas Negri Yogyakata. Yogyakarta

Suriatno, A., \& Yusuf, R. (2018). Pengaruh Latihan Split Squat Jump Terhadap Peningkatan Power Otot Tungkai Dan Ketetapan Smash Dalam Permainan Bola Voly. JISIP (Jurnal Ilmu Sosial dan Pendidikan), 2(1)

Suryadin, T., Sahudi, U., \& Kulyana, K. (2021). Pengaruh Latihan Tendangan Ke Atas Kursi Terhadap Keterampilan Tendangan Depan Pada Ekstrakurikuler Pencak Silat Di Smk Bina Insan Mandiri. Journal RESPECS, 3(2), 45-52. 